\title{
PRINCIPAIS RAZÕES PARA A DOAÇÃO DE ÓRGÃOS EM UMA AMOSTRA POPULACIONAL NA CIDADE DE CAMPINAS/SP
}

\author{
Main reasons for organ donation in a sample from Campinas/SP
}

\author{
Yuri Longatto Boteon', Luiz Carlos dos Santos Junior', Nathalia Carolina Perruche Marchiani', Keila Domingos de Azevedo', Ilka \\ de Fatima Santana Ferreira Boin², Maria Isabel Warwar Pereira ${ }^{3}$, Flavio Cesar de Sá4
}

\begin{abstract}
RESUMO
Introdução: As filas de espera por um órgão para transplante são longas, e muitos indivíduos acabam falecendo durante a espera; em contrapartida, apenas uma pequena porcentagem de potenciais doadores são efetivados, sendo o principal motivo a recusa da família à doação. Objetivo: O objetivo deste trabalho foi avaliar a relevância das principais razões levantadas na literatura para a opção por doar ou não órgãos e os fatores que interferem nessa escolha. Método: Trata-se de um estudo transversal realizado através da aplicação de um questionário composto por uma parte sócio-demográfica e outra que aborda os motivos para doação de órgãos. Foram entrevistados 149 pacientes; a análise estatística foi realizada por tabelas de freqüência, análise descritiva das variáveis contínuas e teste de qui-quadrado para análise da razão de riscos relacionando os grupos doador / não-doador às variáveis estudadas. O nível de significância estatística adotado é de 0,05. Resultado: quarenta e um vírgula dois por cento dos entrevistados tinham a intenção de doar órgãos; os fatores relacionados foram: ter cursado ensino superior e ter conhecimento do tema. A intenção de doar para salvar uma vida foi o motivo que apresentou diferença significativa como relevante para a doação de órgãos. Conclusões: juntamente com uma maior escolaridade, o conhecimento sobre doação de órgãos e o altruísmo foram relacionados como favoráveis à doação de órgãos.
\end{abstract}

Descritores: Transplante de Órgãos; Obtenção de Tecidos e Órgãos; Medicina;

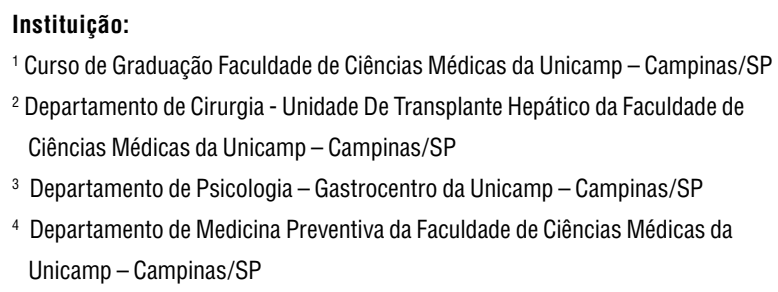

Correspondência:

Yuri Longatto Boteon

Endereço: Rua Malaguias Guerra, 21, Cep:13520-000, São Pedro-SP, Brasil

Tel.: (19) 3296-6690

E-Mail: yurimed43@yahoo.com.br

Recebido em: 10.06 .2010

Aceito em: 05.07.2010

\section{INTRODUÇÃO}

O início dos transplantes deu-se em 1905 com transplante de córnea. Depois vieram os transplantes de rim, coração, fígado, pulmões, pâncreas e intestino. O progresso na terapêutica dos transplantes deu-se com a ampliação do conhecimento a respeito da compatibilidade de tecidos e os medicamentos contra rejeição. ${ }^{1}$ Sabe-se por dados da ABTO (Associação Brasileira de Transplante de Órgãos) que no primeiro semestre de 2010 houve um aumento de $11 \%$ no número de doadores efetivos, ${ }^{2}$ quando comparado ao ano anterior, atingindo-se a cifra de 9,9 doadores por milhão de habitantes. No entanto, esse número não é suficiente para atender à demanda de pacientes em listas de espera. No estado de São Paulo, segundo dados até maio de 2010, havia um total de 12.260 pacientes à espera por um órgão ou tecido, dentre os quais 10.128 aguardam por um rim, outros 1.082 por um fígado, enquanto que 424 necessitam de transplante de córnea. ${ }^{3}$ Não se trata somente da espera por órgãos e tecidos, mas sim da expectativa por uma maior 
chance de sobrevida, com melhor qualidade em seus âmbitos físico, psíquico e social.

Apesar da alta demanda, apenas $28 \%$ dos pacientes que se encontram em Unidades de Terapia Intensiva (UTI) como potenciais doadores se tornam efetivos. ${ }^{2}$ As principais razões para esse baixo aproveitamento de potenciais doadores, segundo dados da ABTO, é a falta de permissão por parte das famílias $(23,7 \%)$ e a ocorrência de parada cardiorrespiratória (19,2\%). Em terceiro lugar, encontrase a contra-indicação médica para a realização da retirada, ${ }^{2}$ pois em virtude de um diagnóstico tardio de morte encefálica ou da manutenção clínica inadequada, os órgãos tornam-se inapropriados para transplante. Segundo um trabalho envolvendo dados sobre espera por um fígado, encontrou-se como principal razão a recusa familiar $(46,6 \%)$, seguida por parada cardiorrespiratória $(28,3 \%) .{ }^{4}$

Os dados apontam para necessidade de esclarecimento da população, a fim de despertar a reflexão consciente, a confiança nesse procedimento e a solidariedade para com aqueles que têm o transplante como uma possibilidade de reorganizar a própria vida.

\section{SUJEITOS E MÉTODO}

\section{Seleção dos sujeitos}

Trata-se de um estudo transversal que foi realizado durante a Feira da Saúde Adolfo Lutz 2007 que ocorreu no Largo do Rosário, na região central da cidade de Campinas, interior do estado de São Paulo, Brasil. O evento objetiva realizar ações de prevenção e saúde, com orientação à população que circula pelo centro da cidade no dia do evento. Os critérios de inclusão foram: consentir em participar da pesquisa e ser maior de 18 anos. O critério de exclusão foi não desejar responder. Os sujeitos foram informados da natureza do estudo, e concordando com os termos propostos, assinaram o Termo de Consentimento Livre e Esclarecido, foram submetidos a um questionário estruturado composto por uma avaliação sóciodemográfica e por treze questões explicadas a seguir.

\section{2- Questionário estruturado}

A ficha de coleta de dados continha em seu início um questionário sócio-demográfico, que abordava as variáveis: a) sexo: masculino e feminino; b) faixa etária, agrupada em: $<$ ou igual a 20 anos, de 21 a 40 anos, de 41 a 60 anos e > 60 anos; c) estado civil: solteiros, casados, separados, viúvos e amasiados; d) escolaridade: nunca frequentou escola, ensino fundamental, ensino médio e ensino superior; e) religião: agnóstico, católico, evangélico, espírita e outras.

A seguir, abordava-se o entrevistado a respeito de sua intenção de ser ou não-doador de órgãos.

Na sequência, as 13 questões sobre doação foram construídas, tomando por base motivos levantados a partir da revisão de literatura, utilizando artigos de 1989 a 2009 pesquisados nas bases Pubmed, Scielo e Lilacs com os unitermos doação de órgãos/razões para doação/psicologia em transplante como razões para a escolha de posicionamento pessoal na doação de órgãos.

Foram aplicadas quatro questões que objetivavam avaliar o conhecimento dos entrevistados sobre temas relevantes sobre doação de órgãos, sendo eles: 1) conhecimento do tema doação de órgãos; 2) conhecimento do conceito de morte encefálica; 3) discussão prévia com a família sobre o tema doação de órgãos; e, 4) influência da religião na escolha de doar ou não órgãos.
As nove questões restantes foram distribuídas em: cinco abordando os fatores indicados na literatura como favoráveis à doação de órgãos, e quatro fatores indicados na mesma como não favoráveis à doação. Os motivos levantados para a doação são apresentados na Figura 1 e os motivos para a não doação são apresentados na Figura 2. A partir deles, foram retirados os temas abordados nas questões que serão detalhados a seguir.

Os temas avaliados como favoráveis à doação foram: 1) doaria para salvar a vida de um receptor em um transplante de órgãos; 2) doaria para melhorar a qualidade de vida de um receptor de órgão; 3) doaria por considerar que após a morte, o corpo pode ser desprovido de apego sentimental (matéria orgânica); 4) doaria por considerar a morte como uma injustiça, e dessa forma a doação poderia dar continuidade de sua vida na terra; 5) doaria pois estaria atribuindo um sentido positivo para a morte.

Os quatro temas avaliados como não favoráveis à doação de órgãos foram: 1) desconfiança no sistema de saúde brasileiro, médicos e estrutura dos hospitais; 2) medo de situações como: retirada de órgãos antes de sua morte, falta de adoção de procedimentos para salvar sua vida, medo de mutilação do corpo e medo de sofrimento; 3) não doaria por considerar o corpo morto como o próprio indivíduo, dispensando-lhe todos os sentimentos que eram atribuídos em vida; 4) não doaria órgãos, pois ao ouvir o assunto, pensa em morte, sentindo desconforto em pensar na idéia.

Os sujeitos foram convidados a atribuir numa escala ordinal, de 0 - mínimo a 10 - máximo, quanto ao valor da intensidade/relevância do tema abordado na questão como motivo para sua escolha pessoal acerca da doação de órgãos.

A escolha dos motivos que foram abordados no questionário, em detrimento a outros também encontrados, se orientou buscando abordar temas relatados como vitais e que puderam ser avaliados por um instrumento como o desse estudo, na qualidade de estudo transversal e abordando sujeitos selecionados numa amostra de população geral.

Figura 1: Razões para a doação de órgãos

I- Continuidade da vida do receptor,' que expressa a intenção de protelar a vida de outro individuo, salvar a vida de outra pessoa;

II- Reaproveitamento de órgãos, ${ }^{5}$ parte da visão de corpo-matéria, na qual este seria apenas matéria orgânicadesprovido quando morto de investimento afetivo, sendo passivel, portanto de ser utilizado por outro individuo que necessite, reaproveitando o órgão;

que necessite, reaproveitando o órgão;

IV- Qualidade da vida do receptor, parte do desejo de melhorar a vida de pessoas que necessitem de um transplante, objetivando ainda findar o sofrimento e diminuir as filas de espera:

V- Razőes religiosas envolvem motivação para a doação partindo de uma formaçăo por valores religiosos (anseio de ajudar o próximo, amar os semelhantes) ${ }^{6,7}$

VI- Informações aos familiares pelos funcionários do serviço de saúde quando do início dos exames para confirmaçăo do diagnóstico de morte encef́álica, ${ }^{8,9}$ possibilitando a construção do processo de luto e evitando 0 choque da informaçăo de morte encefálica anteriormente ao questionamento sobre doação de órgãos, ${ }^{8,9}$ VII- Conhecimento do individuo sobre o processo de doação de órgãos, ${ }^{5,689,10} 0$ conhecimento, ao menos básico, quanto à estruturação do processo de doaçăo, alocação de órgãos e transplante é indicado como fator de diferenciação favorecendo a doaçĩo de órgăo;

VIII- Discussão prévia entre os familiares sobre doação de órgãos, ${ }^{5,10}$ que possibilitaria o conhecimento do desejo entre os familiares sobre 0 assunto, facilitando uma possivel tomada de decisão se necessário; IX- Conhecer pessoas doadoras, ${ }^{5}$ possivelmente fator predisponente a doaçẫo por levar a maior discussão $\mathrm{e}$ conhecimento sobre o tema:

$\mathrm{X}$ - Ajudar outros individuos, ${ }^{67,10}$ anscio de poder aliviar o sofrimento de outra pessoa e possibilitar que outro possa retomar sua vida normalmente;

XI- Desejo de criar um significado positivo para a morte do ente querido ${ }^{6}$ por meio da doação buscar atribuir um sentido positivo aliviando a dor da morte do individuo:

XII- Doação por não aceitar a injustiça a que se considera exposta a familia, ${ }^{6}$ este item é trazido como atitude de revolta à situação da morte considerada com de "quebra da ordem natural";

XIII- Pessoa amada vivendo no corpo de outro, ${ }^{6}$ ao doar os órgãos os individuos cultivariam a sensação de que 0 individuo permaneceria vivendo no corpo de outro:

XIV- Outra razão de ampla relevância é um relacionamento honesto e amigável entre a equipe médica e a família, ${ }^{6,10}$ buscando-se com isso uma boa comunicaçåo entre equipe e familia. ${ }^{9,10}$ 
Figura 2: Razões para a não doação de órgãos

I- Sistema brasileiro de saúde, ${ }^{11}$ referido como gerador de insegurança para a população desfavorecendo a doaçăo de órgàos, sendo levantados principalmente a falta de confiança na habilidade do médico, em diagnosticar morte encefálica, e falta de condiçőes adequadas para transplante em hospitais públicos; Sendo ainda o processo de doação considerado desorganizado, burocrático, desgastante e cansativo,"

II- Razões ligadas ao transplante, "1 causadas por mitos referentes ao procedimento como não haver certera de um destino adequado para o órgão doado, medo de uma morte induzida para a retirada de órgãos, ${ }^{11,9}$ retirada quando a pessoa ainda tem chance de se recuperar, 5 ,11 medo da mutilação do corpo e de sofrimento do indivíduo quando não conheciam o processo de doação, ${ }^{8,10}$

III- Corpo-pessoa, " quando há associação sentimental ao corpo morto, ocorre investimento de energias admitindoo como simbolo representante autêntico do familiar,

IV- Medo da morte," quando o individuo já possui csse medo, pensar em doação de órgãos remete a cste, posicionando-se de maneira mais fácil como não doador, ${ }^{11}$

V-Processo de doação demorado, ${ }^{6}$ fator esse que leva o indivíduo a não doar por querer resolver rapidamente a situação traumática a que se vê exposto:

VI- Desconhecimento do conceito de morte encefálica, ${ }^{6,9} 0$ que prejudica a doação de órgãos porque a família muitas vezes considera como "não morto" o paciente, não permitindo a doação de órgãos;

VII- Outro fator trazido em especial para o Brasil é o das dimensões continentais ${ }^{6}$ de nosso pais com poucos centros transplantadores, 0 que prejudica muitas vezes a efetivação da doação e transplante de órgãos em algumas regiōes;

VIII- Diferenças culturais e sociais também influem no processo de doação, ${ }^{6}$ essas afetam mesmo na abordagem para o questionamento sobre a doação;

IX- A ausência de diálogo sobre o tema na familia ${ }^{6}$ é levantado como fator para a não doação; $e$ ainda leva 0

desconhecimento do desejo de doação dos familiares;"

$\mathrm{X}$ - Razões religiosas ${ }^{10,11}$ motivando atitudes de não doação de órgãos,"

\section{3- Análise estatística}

Os dados obtidos foram analisados por meio de tabelas de freqüência, teste de qui-quadrado e análise do odds ratio relacionando a distribuição dos grupos doador / não-doador com as seguintes variáveis sócio-demográficas: faixa etária, religião, estado civil, sexo e nível de escolaridade. Foram usados testes descritivos do programa Statistics ${ }^{\circledR}$ 7.0. O nível de significância estatística adotado foi de 0,05 .

\section{RESULTADOS}

\section{Análise descritiva geral}

A amostra foi constituída de 149 pacientes. A tabela 1 mostra a divisão dos sujeitos por sexo, faixa etária, estado civil, escolaridade e religião.

Do total de 149 pacientes, encontramos que 62 dos entrevistados $(41,2 \%)$ declararam-se doadores de órgãos, e 87 não-doadores $(58,8 \%)$. Ainda na tabela 1 , é apresentada a distribuição dos grupos estudados, doador e não-doador, de acordo com as variáveis sócio-demográficas.

Tabela 1 - Características socio-demográficas da amostra estudada, distribuição pelos grupos "favorável" ou não à doação e prevalência dessas características.

\begin{tabular}{lccccccc}
\hline Variável $^{*}$ & Amostra total & \multicolumn{2}{l}{ Favorável doação } & Não favorável doação & $P$ \\
\hline & $N=149$ & $\mathbf{1 0 0 \%}$ & $\mathrm{N}=\mathbf{6 2}$ & $\mathbf{1 0 0 \%}$ & $\mathrm{N}=\mathbf{8 7}$ & $\mathbf{1 0 0 \%}$ & \\
\hline Sexo & & & & & & & $\mathrm{NS}$ \\
\hline Masculino & 62 & $41,6 \%$ & 21 & $33,9 \%$ & 41 & $47,1 \% \%$ & \\
Feminino & 87 & $58,4 \%$ & 41 & $66,1 \%$ & 46 & $52,9 \%$ & \\
\hline
\end{tabular}

\begin{tabular}{lccccccc}
\hline Faixa etária & \multicolumn{10}{c}{} & NS \\
\hline$<20$ anos & 14 & $9,4 \%$ & 4 & $6,5 \%$ & 10 & $11,4 \%$ \\
$21-40$ anos & 46 & $30,8 \%$ & 25 & $40,3 \%$ & 21 & $24,1 \%$ \\
$\mathbf{4 1 - 6 0}$ anos & 70 & $47 \%$ & 28 & $45,2 \%$ & 42 & $48,3 \%$ \\
$>60$ anos & 19 & $12,8 \%$ & 5 & $8,1 \%$ & 14 & $16,1 \%$ \\
\hline
\end{tabular}

\begin{tabular}{|c|c|c|c|c|c|c|c|}
\hline Solteiros & 54 & $36,4 \%$ & 20 & $32,8 \%$ & 34 & $39,1 \%$ & \\
\hline Casados & 59 & $39,2 \%$ & 26 & $42,6 \%$ & 32 & $36,8 \%$ & \\
\hline Separado & 18 & $12,2 \%$ & 9 & $14,8 \%$ & 9 & $10,3 \%$ & \\
\hline Viúvo & 12 & $8,1 \%$ & 6 & $9,8 \%$ & 6 & $6,9 \%$ & \\
\hline Amasiado & 6 & $4,1 \%$ & 0 & $0 \%$ & 6 & $6,9 \%$ & \\
\hline \multicolumn{8}{|l|}{ Escolaridade } \\
\hline Sem escolaridade & 2 & $1,4 \%$ & 0 & $0 \%$ & 2 & $2,4 \%$ & $N S^{\epsilon}$ \\
\hline EnsinoFundamental & 62 & $41,1 \%$ & 17 & $27,9 \%$ & 43 & $50,6 \%$ & NS ${ }^{\epsilon}$ \\
\hline Ensino Médio & 54 & $36,3 \%$ & 22 & $36,1 \%$ & 31 & $36,5 \%$ & $N S^{\epsilon}$ \\
\hline Ensino Superior & 31 & $21,2 \%$ & 22 & $36,1 \%$ & 9 & $10,6 \%$ & $<0,05^{\star}$ \\
\hline Religião & & & & & & & NS \\
\hline Agnóstico & 10 & $6,7 \%$ & 3 & $4,8 \%$ & 7 & $8 \%$ & \\
\hline Católico & 77 & $51,7 \%$ & 31 & $50 \%$ & 46 & $52,9 \%$ & \\
\hline Evangélico & 53 & $35,6 \%$ & 20 & $32,3 \%$ & 33 & $37,9 \%$ & \\
\hline Espirita & 6 & $4 \%$ & 5 & $8,1 \%$ & 1 & $1,1 \%$ & \\
\hline Outra religião & 3 & $2 \%$ & 3 & $4,8 \%$ & 0 & $0 \%$ & \\
\hline
\end{tabular}

$¥$ - A porcentagem se refere a cada variável isolada; NS: diferença não-significativa; ${ }^{*} p<0,05$ para o grupo com ensino superior em relação a todos os outros grupos; $€$ dos respectivos grupos com relação a todos os demais grupos.

\section{Análise da influência de fatores sócio-demográficos sobre a opção de doar ou não órgãos}

Quando comparamos os dois grupos em relação à amostra total, encontramos que o fator estatisticamente relacionado com a escolha de doar órgãos foi ter cursado o ensino superior, $(\mathrm{p}=0,013 ; \mathrm{OR}=3$; IC $\{95 \%\} 1,32-6,81)$; não se observou diferença significativa entre eles em relação aos quesitos sexo, faixa etária, estado civil, religião e demais itens da escolaridade. Os dados são apresentados na tabela 1.

\section{Distribuição do conhecimento sobre temas relevantes para a doação de órgãos}

Na tabela 2 está representado o conhecimento que os sujeitos da pesquisa acreditavam ter quando questionados a respeito dos temas doação de órgãos, morte encefálica, discussão com a família acerca de doação de órgãos e influência de sua religião na opção doar/não doar órgãos.

Quando questionados a respeito do conhecimento sobre o tema doação de órgãos, $31,5 \%$ não o conheciam, enquanto $25,5 \%$ dos entrevistados conheciam plenamente o conceito. A média das notas obtidas foi de 4,99 .

Outro conceito que buscamos inferir foi o conhecimento na população estudada sobre morte encefálica, e vimos que 41,6\% não o conheciam, enquanto $35,6 \%$ dos entrevistados conheciam plenamente o termo. A média das notas obtidas foi de 4,95.

Questionados a respeito da discussão com a família acerca do tema doação de órgãos, 47,7\% afirmaram não ter discutido com a família, enquanto $34,9 \%$ dos entrevistados discutiram plenamente. A média das notas obtidas foi de 4,48.

Quanto à religião, 74,5\% dos sujeitos responderam acreditar que sua religião não influenciava sua decisão de doar órgãos e 18,1\% que influenciava. A média das notas obtidas foi de 2,29. 
Tabela 2 - Distribuição de conhecimentos sobre temas relevantes para a doação de órgãos e análise da incidência desses sobre a opção de doação ou não-doação.

\begin{tabular}{|c|c|c|c|c|c|c|c|}
\hline \multirow[t]{2}{*}{ Questões } & \multicolumn{2}{|c|}{ Amostra total } & \multicolumn{2}{|c|}{$\begin{array}{c}\text { Favorável a } \\
\text { doação }\end{array}$} & \multicolumn{3}{|c|}{ Não favorável a doação $p$} \\
\hline & $N=149$ & \multirow{2}{*}{$\begin{array}{l}100 \% \\
\text { órgãos }\end{array}$} & \multirow[t]{2}{*}{$\mathrm{N}=62$} & \multirow[t]{2}{*}{$100 \%$} & \multicolumn{2}{|c|}{$\mathrm{N}=87$} & \\
\hline \multicolumn{5}{|c|}{ Conhecimento do tema doação de órgãos } & & & \\
\hline Não conheciam & 47 & $31,5 \%$ & 9 & $14,5 \%$ & 38 & $43,7 \%$ & ${ }^{*}<0,05$ \\
\hline Conheciam muito pouco & 11 & $7,4 \%$ & 5 & $6,5 \%$ & 6 & $6,9 \%$ & NS \\
\hline Conheciam pouco & 39 & $26,2 \%$ & 19 & $29 \%$ & 20 & $23 \%$ & $\mathrm{NS}^{*}$ \\
\hline Conheciam razoável & 14 & $9,4 \%$ & 9 & $17,7 \%$ & 5 & $5,7 \%$ & $\mathrm{NS}^{¥}$ \\
\hline Conheciam plenamente & 38 & $25,5 \%$ & 20 & $32,3 \%$ & 18 & $20,7 \%$ & $\mathrm{NS}^{*}$ \\
\hline \multicolumn{5}{|c|}{ Conhecimento do conceito de morte encefálica } & & & NS \\
\hline Não conheciam & 62 & $41,6 \%$ & 17 & $27,4 \%$ & 45 & $51,7 \%$ & \\
\hline Conheciam muito pouco & 7 & $4,7 \%$ & 3 & $4,8 \%$ & 4 & $4,6 \%$ & \\
\hline Conheciam pouco & 16 & $10,7 \%$ & 10 & $16,2 \%$ & 6 & $6,9 \%$ & \\
\hline Conheciam razoávelm. & 11 & $7,4 \%$ & 5 & $8,1 \%$ & 6 & $6,9 \%$ & \\
\hline Conheciam plenamente & 53 & $35,6 \%$ & 27 & $43,5 \%$ & 26 & $29,9 \%$ & \\
\hline \multicolumn{5}{|c|}{ Discussão com a família sobre doação de órgãos } & & & NS \\
\hline Nunca discutiram & 71 & $47,7 \%$ & 19 & $30,6 \%$ & 52 & $59,8 \%$ & \\
\hline Discutiram muito pouco & 5 & $3,4 \%$ & 3 & $4,8 \%$ & 2 & $2,3 \%$ & \\
\hline Discutiram pouco & 17 & $11,4 \%$ & 9 & $14,5 \%$ & 8 & $9,2 \%$ & \\
\hline Discutiram razoável & 4 & $2,7 \%$ & 4 & $6,5 \%$ & 0 & $0 \%$ & \\
\hline Discutiram plenamente & 52 & $34,8 \%$ & 27 & $43,6 \%$ & 25 & $28,7 \%$ & \\
\hline \multicolumn{5}{|c|}{ Influência da religião na escolha doar/não órgãos } & & & NS \\
\hline Não influenciava & 111 & $74,5 \%$ & 43 & $69,4 \%$ & 68 & $78,2 \%$ & \\
\hline Influencia muito pouco & 1 & $0,7 \%$ & 1 & $1,6 \%$ & 0 & $0 \%$ & \\
\hline Influenciava pouco & 1 & $0,7 \%$ & 0 & $0 \%$ & 1 & $1,1 \%$ & \\
\hline Influenciava razoável & 5 & $3,4 \%$ & 2 & $3,2 \%$ & 3 & $3,4 \%$ & \\
\hline Influenciava plenamente & 27 & $18,1 \%$ & 12 & $19,4 \%$ & 15 & $17,2 \%$ & \\
\hline
\end{tabular}

NS: Diferença não-significativa; ${ }^{*} p<0,05$ para o grupo que não conheciam o tema doação de órgãos em relação a todos os outros grupos; ¥ dos respectivos grupos com relação a todos os demais grupos.

\section{Análise da influência do conhecimento dos temas relevantes sobre a opção de doar ou não órgãos}

Através do teste de qui-quadrado e análise da razão de riscos, encontramos que o não conhecimento sobre o tema doação de órgãos reduziu a opção por doar em aproximadamente 3 vezes ( $\mathrm{p}=0,013 ; \mathrm{OR}=0,35 ; \mathrm{IC}\{95 \%\} 0,16-0,77)$. Não se observou diferença significativa entre o nível de conhecimento que os indivíduos acreditavam ter sobre o conceito de morte encefálica, discussão prévia com a família sobre o tema doação de órgãos e influência da religião na escolha de doar ou não órgãos sobre a escolha final de ser doador. Os dados são apresentados na tabela 2.

\section{Distribuição e análise dos principais temas levantados como favoráveis ou não para a opção por doar órgãos}

Na tabela 3 são apresentados de forma percentual as respostas positivas para os temas avaliados, sendo de 1 a 5 favoráveis à doação de órgãos explicitados no método, e de 6 a 9 não favoráveis. Esses são tabelados de acordo com sua distribuição na amostra total estudada e nos grupos favoráveis e não favoráveis à doação de órgãos.

Através do teste de qui-quadrado e análise de razão de riscos, encontramos que o único tema que apresentou diferença estatisticamente significativa entre o grupo de indivíduos favoráveis à doação de órgãos e a amostra total estudada foi a intenção de doar para salvar a vida de um receptor em um transplante $(\mathrm{p}=0,016 ; \mathrm{RR}=$ $1,12$; IC $\{95 \%\} 1,06-1,18)$. Ao comparar os grupo de sujeitos, que tinham a intenção de se tornar doadores e não-doadores, observouse também diferença estatisticamente significativa $(\mathrm{p}=0,00 ; \mathrm{R}=$ 1,23; IC $\{95 \%\} 1,11$ - 1,35) quanto a intenção de doar para salvar a vida de um receptor.

Quanto aos outros temas avaliados não foi observada diferença estatisticamente significativa na sua positividade influenciando a opção por doar ou não órgãos, quando comparados com a amostra total estudada.

Tabela 3- Distribuição e análise dos principais temas levantados como favoráveis ou não para a opção por doar órgãos.

\begin{tabular}{|c|c|c|c|c|c|c|c|}
\hline \multirow[t]{2}{*}{ Questões } & \multicolumn{2}{|c|}{ Amostra total } & \multicolumn{2}{|c|}{$\begin{array}{l}\text { Favorável a } \\
\text { doação }\end{array}$} & \multicolumn{2}{|c|}{$\begin{array}{c}\text { Não favorável a } \\
\text { doação }\end{array}$} & \multirow[b]{2}{*}{$p$} \\
\hline & N 149 & $100 \%$ & N 62 & $\%$ & N 87 & $100 \%$ & \\
\hline $\begin{array}{l}\text { 1) Doaria para salvar a vida de um } \\
\text { receptor em um transplante }\end{array}$ & 133 & $89,3 \%$ & 62 & $100 \%$ & 71 & $81,6 \%$ & ${ }^{*}<0,05$ \\
\hline $\begin{array}{l}\text { 2) Doaria para melhorar a qualidade de } \\
\text { vida de um receptor }\end{array}$ & 127 & $85,2 \%$ & 57 & $91,9 \%$ & 70 & $80,5 \%$ & NS \\
\hline $\begin{array}{l}\text { 3) Doaria por considerar que após a } \\
\text { morte o corpo pode ser desprovido de } \\
\text { apego sentimental }\end{array}$ & 132 & $88,6 \%$ & 59 & $95,2 \%$ & 73 & $83,9 \%$ & NS \\
\hline $\begin{array}{l}\text { 4) Doaria por considerar a morte } \\
\text { como uma injustiça, a doação seria a } \\
\text { continuidade da vida na Terra }\end{array}$ & 102 & $68,5 \%$ & 42 & $67,7 \%$ & 60 & $69 \%$ & NS \\
\hline $\begin{array}{l}\text { 5) Doaria pois estaria atribuindo um } \\
\text { sentido positivo para a morte. }\end{array}$ & 45 & $30,2 \%$ & 16 & $25,8 \%$ & 29 & $33,3 \%$ & NS \\
\hline $\begin{array}{l}\text { 6) Desconfiança no sistema de saúde } \\
\text { brasileiro, médicos e estrutura dos } \\
\text { hospitais }\end{array}$ & 71 & $47,7 \%$ & 26 & $41,9 \%$ & 45 & $51,7 \%$ & NS \\
\hline $\begin{array}{l}\text { 7) Medo de situações como: retirada } \\
\text { de órgãos antes de sua morte, falta de } \\
\text { adoção de procedimentos para salvar } \\
\text { sua vida, mutilação do corpo e de } \\
\text { sofrimento }\end{array}$ & 77 & $51,7 \%$ & 28 & $45,2 \%$ & 49 & $56,3 \%$ & NS \\
\hline $\begin{array}{l}\text { 8) Não doaria por considerar o corpo } \\
\text { morto o próprio indivíduo }\end{array}$ & 28 & $18,8 \%$ & 9 & $14,5 \%$ & 19 & $21,8 \%$ & NS \\
\hline $\begin{array}{l}\text { 9) Não doaria órgãos pois ao ouvir o } \\
\text { assunto pensa em morte, sentindo } \\
\text { desconforto em pensar na idéia }\end{array}$ & 38 & $25,5 \%$ & 11 & $17,7 \%$ & 27 & $31 \%$ & NS \\
\hline
\end{tabular}

NS: Diferença não-significativa; * $p<0,05$ para o grupo favorável à doação de órgãos em relação a amostra total estudada.

\section{DISCUSSÃO}

Em nossa amostra populacional encontramos a intenção de doar órgãos em $41 \%$ dos entrevistados, em comparação com a taxa de $70 \%$ descrita na literatura em estudos internacionais. ${ }^{12}$ Em um estudo conduzido com estudantes de medicina no nordeste do Brasil encontrou-se que $69,2 \%$ desejavam ser doadores de órgãos. ${ }^{13}$ Outro estudo que avaliou o conhecimento da população na cidade de Curitiba/PR encontrou que $87,8 \%$ dos entrevistados eram favoráveis a doação de órgãos. ${ }^{14}$

Uma das variáveis associados ao maior grau de intenção de doar órgãos foi ter cursado nível superior, sendo que nesse grupo, a chance de ser doador foi três vezes maior do que a da amostra estudada. Resultados semelhantes foram encontrados em outros estudos, tanto brasileiros ${ }^{14}$ como internacionais. ${ }^{15}$

A outra variável associada de forma indireta com maior grau de intenção de doar órgãos foi o conhecimento a respeito do tema doação de órgãos, sendo que se encontrou que não conhecer o 
tema reduzia em 3,5 vezes a chance de ser doador. Já há relatos na literatura internacional sobre a influência do conhecimento desse tema no processo de doação de órgãos ${ }^{16}$ desde 1985 . O conhecimento do indivíduo sobre o processo de doação de órgãos é indicado em vários estudos como fator de favorecimento à doação. ${ }^{9,10,11,17}$ Não se estabeleceu relação estatística entre a opção por doar órgãos e variáveis como sexo, idade, estado civil, religião, discussão prévia com a família a respeito do tema e conhecimento a respeito do conceito de morte encefálica. Essa falta de relação deve ser analisada cuidadosamente, dado o número de sujeitos que participaram do estudo. A falta de relação entre religião e doação de órgãos é condizente com a literatura prévia, ${ }^{11,16}$ sendo que abertamente contra a doação de órgãos seriam apenas os judeus ortodoxos.

Na literatura é encontrada associação entre a discussão prévia com a família e a opção por doar órgãos, ${ }^{10,11}$ sendo esta associada como fator facilitador, o mesmo se verificando em relação ao conhecimento do tema morte encefálica. ${ }^{6,9}$ Encontramos que a média atribuída a esses dois temas foi baixa entre os entrevistados: $41,6 \%$ não conheciam o conceito de morte encefálica e $47,7 \%$ nunca haviam discutido com a família a respeito de doação de órgãos, condições que podem se refletir na taxa de intenção de doar encontrada no estudo.

Verificamos uma diferença significativa entre o grupo de indivíduos que tinham a intenção de doar órgãos quando comparado a amostra populacional total, quanto ao interesse de salvar a vida de outro indivíduo como motivo para a doação de órgãos; o mesmo foi encontrado em outro estudo sobre o tema. ${ }^{11}$ Esse último motivo, aliado ao interesse de melhorar a qualidade de vida do receptor foi encontrado como razão para a doação de órgãos em um estudo brasileiro $^{14} \mathrm{e}$ em outros da literatura internacional. ${ }^{6,10}$

\section{CONCLUSÃo}

Diante do exposto, podemos concluir que o altruísmo foi a razão que se destacou para a doação de órgãos. Ela deve ser incentivada através de campanhas que esclareçam a população acerca da doação de órgãos, incentivando que o assunto entre nas casas e seja discutido entre os familiares.

\section{ABSTRACT}

Introduction: The waiting time for an organ is long, and many individuals die before surgery. On the other hand, only a small percentage of potential donors are effectively performed. The main reason for such paradox is the families' disagreement on the organ donation. Purpose: to assess the relevance of the main reasons raised in the literature whether to donate or not organs, and the factors that interfere in such a choice. Methods: This is a cross section study based on answers pertained to a structured questionnaire with socio-demographic questions and also some questions about the reasons whether to donate or not. One-hundred and forty-nine subjects were interviewed; the statistical analysis was performed by analyzing the frequency tables, analytical description of continuous variables and applying the quisquare on the related risk correlating donor / non-donor groups to the variables. Statistic significance level adopted was 0.05. Results: It was found that forty-one point two percent of individuals were willing to the organ donation; the associated factors were higher education level and knowledge on the organ donation issues. Intention to donate organs to save lives was the most relevant factor that contributed for the organ donation. Conclusions: Along with higher education level, the knowledge on the organ donation and altruistic issues were elements favorable to the organ donation.

Keywords: Organ Transplantation; Tissue and Organ Procurement; Medicine

\section{REFERÊNCIAS}

1. Bollinger R. Transplante: aspectos históricos. In Sabiston D.C. Tratado de cirurgia. 14 ed. Rio de janeiro: Guanabara Koogan, 1991;18:319-25

2. Associação Brasileira de Transplante de Órgãos. São Paulo: ABTO. Acesso em 14/07/2009. Registro Brasileiro de Transplantes - Janeiro-Junho de 2010. Disponível em: http://www.abto.org.br/abtov02/portugues/profissionais/rbt/mensagemRestrita. aspx?idCategoria $=2$.

3. Sistema Estadual de Transplantes - Secretaria de Estado da Saúde do Estado de São Paulo. Lista de espera para transplante, com doador cadavérico, no Estado de São Paulo. Acessado em 14/07/2009. Disponível em : http://portal.saude.sp.gov.br/content/cidadao_ extras_servicos_informacoes_orientacoes_transplantes_lista_espera_orgao_cornea. $\mathrm{mmp}$

4. Boin ID, Palmiero HD, Kajikawa P, Zambelli HJ. Reviewing the Causes for 1432 Discharged Liver Donors: Can Donations be Increased? Transplantation Proceedings. 2009;v.41,p.797-8.

5. Nolan BE, Spanos NP. Psychosocial variables associated with willingness to donate organs. CAMJ. 1989,July 1;141:27-32.
6. Bellalia T, Papadatou D. The decision-making process of parents regarding organ donation of their brain death child: a greek study. Social science \& Medicine. 2007 Jan;64(2):439-50.

7. Morgan SE, Harrison TR, Afifi WA, Long SD, Stephenson MT. In Their Own Words: The Reasons Why People Will (Not) Sign an Organ Donor Card. Health Communication. 2008;23(1):23-33

8. Schauenburg H, Hildebrant A. Public knowledge and attitudes on organ donation do not differ in German and Spain. Transplantation Proceedings. 2006;38(5):1218-20.

9. Simpkin AL, Robertson LC, Barber VS, Young JD. Modifiable factors influencing relatives' decision to offer organ donation: systematic review. BMJ. 2009;338:b701

10. Siminoff L, Mercer MB, Graham GMA, Burant CMA. The Reasons Families Donate Organs for Transplantation: Implications for Policy and Practice. The Journal of Trauma: Injury, Infection, and Critical Care. 2007;62(4):969-78.

11. Bendassolli PF. Percepção do corpo, medo da morte, religião e doação de órgãos. Psicologia: reflexão e crítica. 2001;14(1):225-40. 
12. Saleem T, Ishaque S, Habib N, Hussain SS, Jawed A, Khan AA, et al. Knowledge, attitudes and practices survey on organ donation among a selected adult population of Pakistan. BMC Medical Ethics. 2009;17(10):5

13. Dutra MMD, Bonfim TA, Pereira IS, Figueiredo IC, Dutra AMD, Lopes AA. Knowledge about transplantation and attitudes toward organ donation: a survey among medical students in northeast Brazil.Transplantation Proceedings. 2004;36:818-20.

14. Coelho JCU, Cilião C, Parolin MB, Freitas ACT, Gama Filho OP, Saad DT, et al. Opinião e conhecimento da população da cidade de Curitiba sobre doação e transplante de órgãos. Rev Assoc Med Bras. 2007;53(5):421-5
15. Saleem T, Ishaque S, Habib N, Hussain SS, Jawed A, Khan AA, et al. Knowledge, attitudes and practices survey on organ donation among a selected adult population of Pakistan. BMC Medical Ethics. 2009;17(10):5.

16. Bülow HH, Sprung CL, Reinhart K, Prayag S, Du B, Armaganidis A, et al. The world's major religions' points of view on end-of-life decisions in the intensive care unit. Intensive Care Med. 2008;34(3):423-30

17. Santos MJ, Massarollo MCKB. Processo de doação de órgãos: percepção de familiares de doadores cadáveres. Revista Latino Americana de Enfermagem. 2005;13(3):382-7. 